\title{
Plasma level of prostate related-antigen peptide-reactive IgG is a prognostic factor of patients with breast cancer treated with personalized peptide vaccines
}

\author{
SHUKO SAKU ${ }^{1 *}$, UHI TOH $^{1 *}$, YUKO TAKAO $^{1}$, SAYAKA SAKURAI $^{1}$, AKIRA YAMADA $^{2}$, \\ SHIGEKI SHICHIJO ${ }^{3}$, KYOGO ITOH ${ }^{3}$ and YOSHITO AKAGI ${ }^{1}$ \\ ${ }^{1}$ Department of Surgery; ${ }^{2}$ Research Center for Innovative Cancer Therapy; ${ }^{3}$ Cancer Vaccine Center, \\ Kurume University School of Medicine, Kurume, Fukuoka 830-0011, Japan
}

Received March 8, 2020; Accepted August 6, 2020

DOI: $10.3892 / \mathrm{etm} .2021 .10337$

\begin{abstract}
The present study assessed plasma IgG in patients with metastatic recurrent breast cancer $(\mathrm{mrBC})$ that is reactive to various T-cell epitope peptides of prostate-related antigens (PRAs), such as prostate-specific antigen, prostate-specific membrane antigen and prostate acid phosphatase. Patients were treated with personalized peptide vaccines (PPVs) which were selected and administered from a panel of candidate peptides based on human leukocyte antigen-types and prevaccination IgG levels to each peptide. The peptide panel consisted of 27 cytotoxic T-lymphocyte-epitope peptides derived from tumor-associated antigens, not including PRA. PRA peptides and peptide panels were retrospectively analyzed in 77 PPV-treated patients. The results revealed that PRA reactive $\operatorname{IgG}$ levels were increased after vaccination in 31 of the 97 patients included in the present study. Although there was no significant association between anti-PRA peptide levels and progression-free survival (PFS) or overall survival, anti-PRA peptide levels were significantly associated with
\end{abstract}

Correspondence to: Dr Uhi Toh, Department of Surgery, Kurume University School of Medicine, 67 Asahi-machi, Kurume, Fukuoka 830-0011, Japan

E-mail: utoh@med.kurume-u.ac.jp

*Contributed equally

Abbreviations: ANA, anastorozole; EXE, exemestane; HER2, human epidermal growth factor 2; HLA, human leukocyte antigen; LET, letrozole; mrBC, metastatic recurrent breast cancer; OS, overall survival time; PAP, prostatic acid phosphatase; PFS, progression-free survival time; PPV, personalized peptide vaccination; PRA, prostate-related antigen; PSA, prostate-specific antigen; PSMA, prostate-specific membrane antigen; RANKL, receptor activator of NK-kB ligand; TAA, tumor-associated antigen; TNBC, triple-negative breast cancer

Key words: metastatic recurrent breast cancer, peptide vaccination, antigen spreading response, prostate-related antigen
PFS $(\mathrm{P}=0.009)$ in estrogen-receptor positive $(\mathrm{ER}+)$ patients with cancer. The results suggested that plasma anti-PRA IgG levels may be a useful prognostic marker for monitoring PPVs, particularly for ER+ patients with $\mathrm{mrBC}$ (trial registration no. from the UMIN Clinical Trials Registry, UMIN000001844).

\section{Introduction}

Breast cancers often produce prostate-related antigens, including prostate-specific antigen (PSA), prostate-specific membrane antigen (PSMA), and prostate acid phosphatase (PAP), and the serum level of PSA has been suggested to be a breast cancer prognostic marker (1-4). Although several studies have indicated that the presence of antigen spreading response after the administration of a vaccine against PSA could influence the outcomes of patients with prostate cancer $(5,6)$, the immune response to these prostate-related antigens (PRAs) in patients with metastatic recurrent breast cancer (mrBC) has rarely been investigated. In 2014 we conducted a phase II study of personalized peptide vaccination (PPV) for mrBC patients, the results of which indicated that the median progression-free survival (PFS) and median overall survival (OS) were 7.5 and 15.9 months, respectively; in addition, an enhanced number of cytotoxic T lymphocytes (CTLs) and/or an increased IgG response was observed after the vaccination in most of the patients, irrespective of the breast cancer subtype (7).

Most of the peptides used for PPV therapy are commonly expressed in various types of advanced cancers, and we demonstrated the safety and feasibility of a PPV for patients with advanced cancer in our previous phase II clinical trials (8-11). The PPV regimen used individually selected vaccine antigens, chosen from a panel of peptide candidates applicable for the human leukocyte antigen (HLA)-A2, -A24, -A26, -A3, -A11, -A31 and -A33 patients, based on the patients' pre-existing host immunity and HLA-A types. Although a panel used for the peptide vaccination in the present study did not include PRA peptides since no expression of PRA in $\mathrm{mrBC}$ had been suggested by our preliminary studies (7), we analyzed the pre- and postvaccination plasma levels of antigen-specific IgG to PRA peptides of the original panel for common cancer vaccines and their potential as prognostic 
biomarkers of cancer vaccine therapy for mrBC patients. Our findings suggest that the plasma anti-PRA peptide IgG is a possible prognostic marker for monitoring the outcomes of peptide vaccine therapy in $\mathrm{mrBC}$ patients.

\section{Patients and methods}

Patients and datasets. A total of $79 \mathrm{mrBC}$ patients with metastases who had failed standard chemotherapy and/or hormonal therapy were vaccinated as PPV therapy. A maximum of four HLA-matched peptides showing high peptide-specific $\mathrm{IgG}$ responses in the prevaccination plasma were selected from a panel of 31 peptides (Table SI) applicable for the four HLA-A2, -A24, -A26, -A3, -A11, -A31 and -A33 types followed by subcutaneous administration once a week for 6 weeks and once every 2 weeks thereafter. All patients were positive for HLA-A2, -A24, -A26, -A3, -A11, -A31, or -A33. Enrolled patients were required to show at least two positive IgGs reactive to the different vaccine peptides in prevaccination plasma, as reported (7-12).

We collected and analyzed the data from the $77 \mathrm{mrBC}$ patients who received PPV therapy. Eligible patients were aged 20 years or older with histologically confirmed advanced metastatic breast cancer, and had an Eastern Cooperative Oncology Group (ECOG) performance status (PS) of 0 or 1 , life expectancy of at least 12 weeks, and adequate bone marrow function, hepatic function and renal function. Exclusion criteria included acute infection, history of severe allergic reactions, pulmonary, cardiac or other systemic diseases, or other inappropriate conditions for enrollment as judged by clinicians (7). We divided these patients into three different intrinsic subtypes: Estrogen-receptor-positive $\left(\mathrm{ER}^{+}\right) / \mathrm{HER} 2-$ negative (HER2-), HER2-positive (immunohistochemical score $3+$ or HER 2 gene/chromosome 17 ratio $>2.2$ in fluorescence in situ hybridization: HER $2^{+}$), and triple-negative (hormone-receptor-negative and HER2-negative: TNBC). A total of 77 patients were subgrouped as the TNBC $(n=18)$, $\mathrm{ER}^{+} / \mathrm{HER}^{-}(\mathrm{n}=44)$, and HER2 ${ }^{+}(\mathrm{n}=15)$ groups. The clinical evaluation of the disease progression, new lesions of the recurrence was performed in each follow-up according to the study protocol for all cases $(7,8)$.

Measurement of peptide-reactive $\operatorname{Ig} G$. We determined the plasma $\mathrm{IgG}$ levels reactive to the 31-vaccine peptide panel with CTL-epitope peptides, including PSA-248, PSMA-624 and PAP-213, and PAP-248 by assessing the fluorescence intensity unit (FIU) values obtained with a Luminex system (Luminex) as described $(13,14)$. If the peptide-reactive $\operatorname{IgG}$ level in the postvaccination plasma was more than twofold higher than that of prevaccination level, the levels were considered increased, as reported (9-12).

Statistical analyses. The Mann-Whitney U test was used to examine the statistical differences in continuous and categorical values, respectively. A P-value $<0.05$ was considered significant. The PFS and OS were calculated from the date of the first vaccination until the date of disease progression or death, respectively, or the last date when the patient was known to be alive. The survival analysis was performed with the Kaplan-Meier method, and a comparison of the survival curves was performed with the log-rank test. Statistical tests were performed using JMP Pro software, ver. 11 (SAS Institute Inc.). The Cox proportional hazard analysis was used for a univariate analysis to identify clinically relevant factors: Age, performance status, anti-PRAs antibody IgG, pathological intrinsic subtype, total number of metastases, the median time to the first PPV from recurrence, and the median duration of previous chemotherapies. All analyses were also stratified for concurrent treatment: The regimen numbers of previous chemotherapies, hormonal therapies, anti-HER2 therapies, and bisphosphonate acid or anti-RANKL antibody therapies. The interaction showed a univariate significant difference between the outcomes and relevant factors, which we analyzed in a multivariable model.

\section{Results}

Patient characteristics. Seventy-seven mrBC patients with a median age of 57 years (range 30-77 years) were comprised the patient series. After the 6 and 12th vaccinations, the sum of the plasma levels of anti-PRA IgG had significantly increased in 31 patients (the 'anti-PRA increase group'), whereas these levels did not increase in the remaining 46 patients (the 'anti-PRA no-increase group'). The patient characteristics of the two groups are summarized in Table I.

The anti-PRA increase group consisted of 18 (58.1\%) $\mathrm{ER}^{+} / \mathrm{HER} 2-$ patients, seven $(22.5 \%) \mathrm{HER}^{+}$patients, and six (19.4\%) TNBC patients. In contrast, the anti-PRA no-increase group consisted of $30(65.2 \%) \mathrm{ER}^{+} / \mathrm{HER} 2$-patients, five (10.9\%) HER2+ patients, and $11(23.9 \%)$ TNBC patients (Table I). The combined therapies included chemotherapy, anti-HER2 therapy, hormone therapy, and bisphosphonate $\left(\right.$ Zometa $\left.^{\circledR}\right)$ or anti-RANKL therapy ( $\operatorname{Ranmark}^{\circledR}$ ), also shown in Table I. Compared to the anti-PRA no-increase group, the anti-PRA increase group included a significantly large number of HER2 ${ }^{+}$ patients $(\mathrm{P}=0.020)$ and a significantly higher frequency of patients who received concurrent combined bisphosphonate or anti-RANKL therapy $(\mathrm{P}=0.004)$. There were no significant between-group differences in age $(\mathrm{P}=0.582)$, intrinsic $\mathrm{ER}^{+} / \mathrm{HER}^{-}(\mathrm{P}=0.068)$ or triple-negative $(\mathrm{P}=0.892)$ subtype, the median number of metastases $(\mathrm{P}=0.573)$, the median duration or number $(\mathrm{P}=0.300)$ of previous chemotherapy treatments, the combined number of concurrent chemotherapy regimens $(\mathrm{P}=0.494)$, anti-HER2 therapy (trastuzumab) $(\mathrm{P}=0.143)$, or hormonal therapies $(\mathrm{P}=0.164)$.

Combination hormonal therapy was used for a total of $39(50.7 \%)$ of the ER+/HER2-negative patients (18 anti-PRA increase patients and 21 anti-PRA no-increase patients) using an aromatase inhibitor such as anastrozole for 10 anti-PRA increase patients and 14 anti-PRA no-increase patients, and letrozole for four anti-PRA increase patients and five anti-PRA no-increase patients. Fulvestrant, a selective estrogen receptor downregulator, was used for one patient in each group, and a high dose of toremifene was given to one anti-PRA no-increase patient. In addition, the median length of PPV therapy showed no significant difference $(\mathrm{P}=0.885)$ between the two groups (Table I).

Plasma IgG levels reactive to PSA, PSMA, and PAP peptides. The plasma $\mathrm{IgG}$ reactive to the peptide panel including 
Table I. Characteristics of patients with mrBC for the anti-PRA increase group and the anti-PRA no-increase group.

\begin{tabular}{|c|c|c|c|}
\hline Variable & $\begin{array}{l}\text { Anti-PRA increase group } \\
\qquad(\mathrm{n}=31)\end{array}$ & $\begin{array}{l}\text { Anti-PRA no-increase group } \\
\qquad(\mathrm{n}=46)\end{array}$ & P-value ${ }^{a}$ \\
\hline Median age (range), years & $59(35-74)$ & $55.5(30-76)$ & 0.582 \\
\hline Ductal carcinoma & 29 & 42 & - \\
\hline Lobular carcinoma & 1 & 2 & - \\
\hline Others & 1 & 2 & - \\
\hline ER positive/HER2 negative, n (\%) & $18(58.1)$ & $30(65.2)$ & 0.068 \\
\hline HER-2 positive, n (\%) & $7(22.5)$ & $5(10.9)$ & 0.020 \\
\hline Triple negative, n (\%) & $6(19.4)$ & $11(23.9)$ & 0.892 \\
\hline Median number of metastatic sites (range) & $3(1-4)$ & $2(1-4)$ & 0.573 \\
\hline $\begin{array}{l}\text { Median duration of previous chemotherapies, } \\
\text { months (range) }\end{array}$ & $12(3-48)$ & $11(2-148)$ & - \\
\hline $\begin{array}{l}\text { Number of previous chemotherapy regimens, } \\
1-3 / \geq 4\end{array}$ & $6 / 18$ & $12 / 19$ & 0.300 \\
\hline Chemotherapy, n (oral/infusion) & $25(18 / 7)$ & $34(19 / 15)$ & 0.494 \\
\hline Anti-HER2 therapy & 7 & 5 & 0.143 \\
\hline Hormonal therapy & 18 & 21 & 0.164 \\
\hline Bisphosphonate/anti-RANKL therapy & 14 & 7 & 0.004 \\
\hline Median numbers of peptide vaccination (range) & $12(2-39)$ & $14(2-30)$ & 0.885 \\
\hline
\end{tabular}

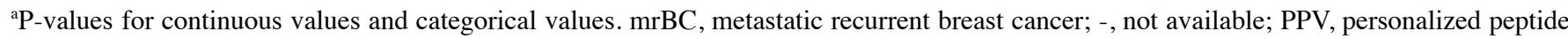
vaccine; PRA, prostate related antigen; ER, estrogen receptor; Bisphosphonate, Zometa ${ }^{\circledR}$; Anti-RANKL therapy: Denosumab Ranmark ${ }^{\circledR}$.

the four PRA peptides (PSA-248, PSMA-624, PAP-213, and PAP-248) were analyzed in the plasma samples from prevaccination $(n=77)$, the post- 6 th $(n=75)$, and the post- 12 th vaccinations $(n=53)$. The plasma IgG levels against anti-PRA peptides showed a remarkable increase in the 31 patients (anti-PRA increase group) at the 6 and 12th vaccination, even though these peptides had not been used for the vaccinations. An increase in anti-PRA IgG was observed irrespective of the intrinsic subtypes of mrBC (Fig. 1A and B). The total plasma anti-PRA IgG levels of the post- 6 and 12 th vaccinations were markedly increased compared to the prevaccination values (Fig. 1A). An increase in the sum of anti-PRA IgG after the 6 and 12th vaccinations was also observed in each intrinsic mrBC subtype group (Fig. 1B).

An increase in $\mathrm{IgG}$ reactive to the PAP (PAP-213 and/or -248), PSA248, and PSMA624 peptides after the 12 th vaccination was observed in 17 of $31(54.8 \%), 11$ of 31 $(35.5 \%)$, and three of $31(9.7 \%)$ patients, respectively. The rates of increase for each subtype of $\mathrm{mrBC}$ are as follows: $58.1 \%$ (18 of the 31 ) patients in the $\mathrm{ER}^{+} / \mathrm{HER} 2$-subtype, $22.5 \%$ (seven of the 31 ) in the HER $2^{+}$subtype, and $19.4 \%$ (six of the 31) in the TN subtype. There was no significant correlation between the subtype and the increase of anti-IgG response (Table SII). On the other hand, no augmentation of the anti-PRA response was observed in the remaining 46 patients (data not shown).

Survival analyses by total anti-PRA IgG level and intrinsic $m r B C$ subtype. At the time of the present analyses, the median duration of follow-up was 33.5 months, the median PFS was 7.4 months, and the median OS was 13.4 months.
No significant differences in PFS or OS were observed among the intrinsic mrBC subtypes, i.e., the ER+/HER2-, HER2+, and TN subtypes, which is consistent with our previous study (7).

The PFS and OS of the anti-PRA increase group were 8.1 and 14.3 months, and those of the anti-PRA no-increase group were 5.1 and 10.8 months (log-rank $\mathrm{P}=0.059$ and $\mathrm{P}=0.082$ ), respectively, with no significant between-group differences (Fig. 2A and B). In contrast, the PFS and OS of the patients with the ER ${ }^{+} / \mathrm{HER} 2-\mathrm{HER}^{+}$, and TN subtypes were 13.6 and 26.5, 4.8 and 13.7, and 8.1 and 12.1 months, respectively, in the anti-PRA increase group, whereas those of the anti-PRA no-increase group were 7.4 and 14.3, 10.4 and 10.7, and 5.0 and 6.4 months, respectively (Fig. 3). The survival curve for PFS (log-rank $\mathrm{P}=0.009$; Fig. 3 ) but not OS (log-rank $\mathrm{P}=0.154)$ of the ER+/Her2-subtype was significantly longer than those of other subtypes in the anti-PRA increase group. In contrast, such significance was not observed in the anti-PRA no-increase group, regardless of the mrBC subtypes in PFS $(\mathrm{P}=0.169)$ and $\mathrm{OS}(\mathrm{P}=0.144)$. In addition, no significant difference was found among the IgG levels against each single PRA in PFS and/or OS.

Association of plasma anti-PRA IgG and clinical factors with the patients' prognoses. Cox regression for survival analysis was performed to investigate the effect of multiple variables included anti-PRA IgG and clinical factors associated with the events that happened. As shown in Table II, the multivariate analyses for the PFS of all 77 patients showed that age over 60 years, anti-PRA IgG, HER2 positivity, number of previous chemotherapy regimens, and duration of vaccine therapy were 
A

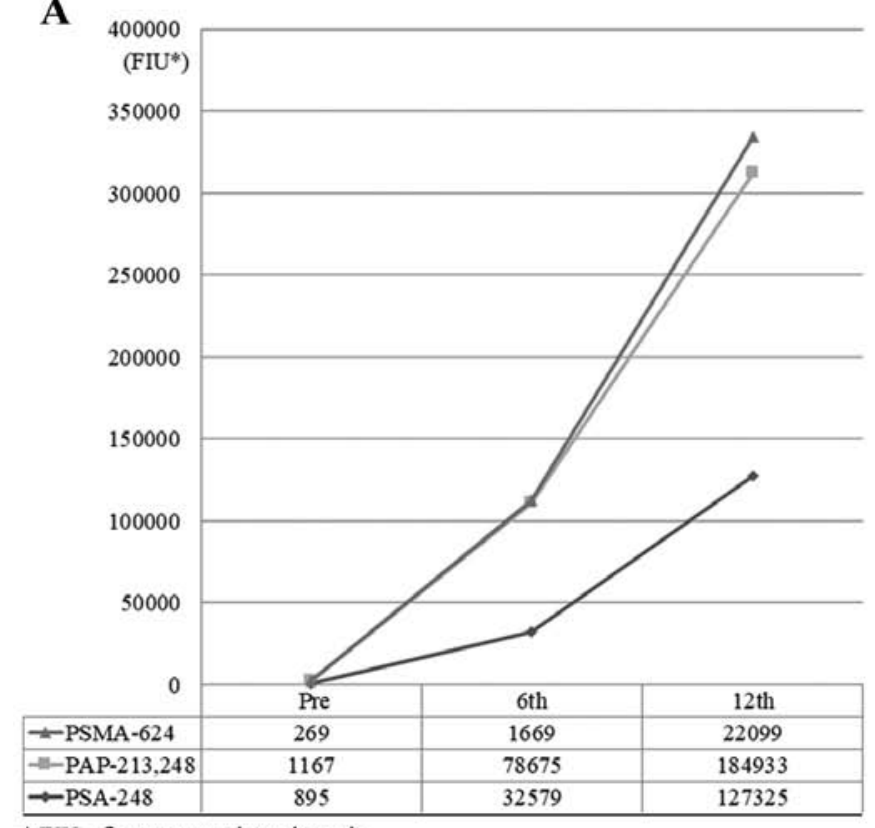

B

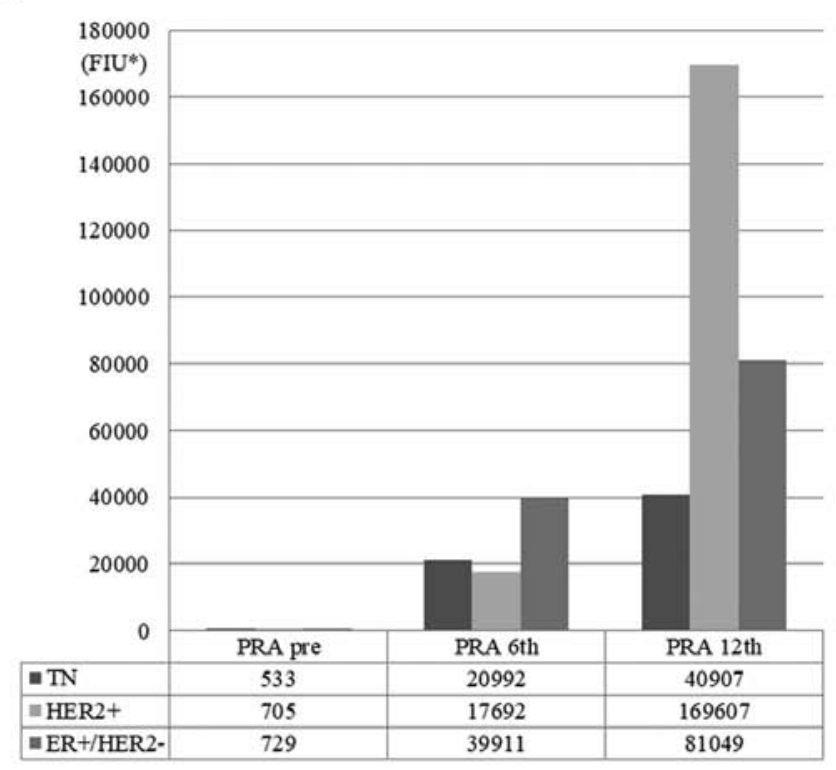

Figure 1. Anti-PRA IgG responses before and after PPV treatment. After 6 and 12 cycles of PPV therapy, total plasma levels of anti-PRA IgG significantly increased in 31 patients with mrBC (anti-PRA increase group). (A) Plasma IgG levels for anti-PMSA-624, anti-PAP-213/-248 and anti-PSA-248 before and after the 6 and 12th vaccinations. (B) Total plasma IgG levels including anti-PMSA-624, anti-PAP-213/-248 and anti-PSA-248 in patients with TN, HER2+ and ER+/HER2-subtypes before and after the 6 and 12th vaccinations. PRA, prostate related antigen; PPV, personalized peptide vaccine; mrBC, metastatic recurrent breast cancer; PMSA, prostate-specific membrane antigen; PAP, prostatic acid phosphatase; PSA, prostate specific antigen; TN, triple negative; ER, estrogen receptor; FIU, fluorescence intensity unit.

A

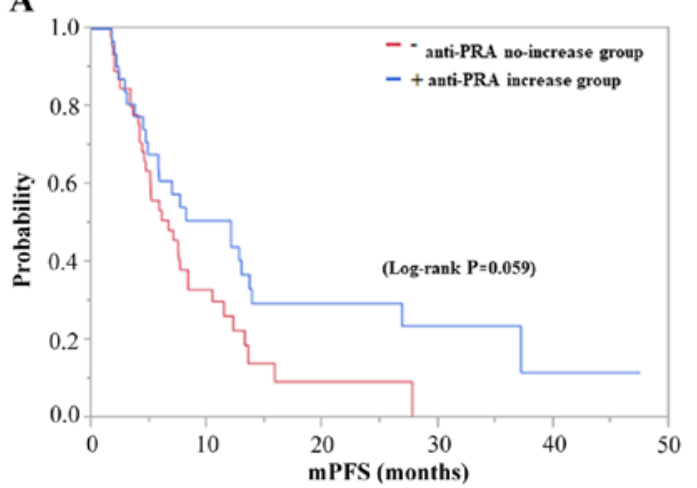

B

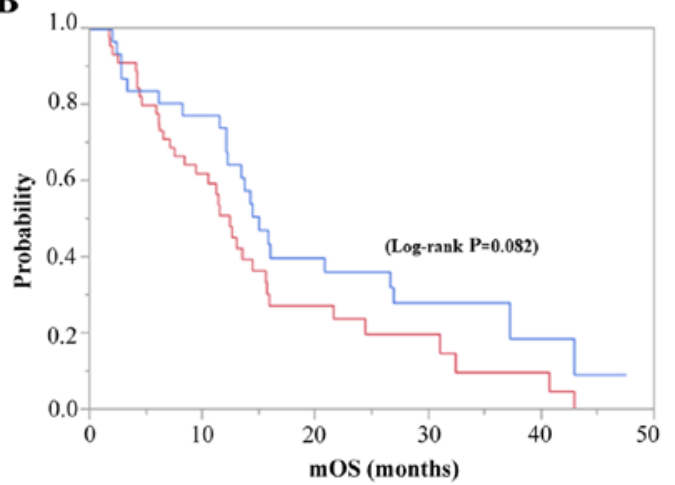

Figure 2. Survival curve analyses with anti-PRA IgG response after PPV therapy. (A) Median PFS of the anti-PRA increase group (n=31) was 8.1 months and the anti-PRA no-increase group $(\mathrm{n}=46)$ was 5.1 months (log-rank, $\mathrm{P}=0.059)$. (B) Median OS of the anti-PRA increase group was 14.3 months, whereas that of the anti-PRA no-increase group was 10.8 months (log-rank, $\mathrm{P}=0.082)$. PRA, prostate related antigen; PPV, personalized peptide vaccine; PFS, progression free survival; OS, overall survival; m, median.

each prognostic factors for PFS $(\mathrm{P}=0.03,0.039,0.023,0.029$, and 0.001 , respectively). The analysis of OS showed that the age, duration of vaccine therapy, anti-HER2 therapy, concurrent standard hormonal therapy, and bisphosphonate and/or anti-RANKL therapy were each prognostic factors for OS $(\mathrm{P}=0.025,0.0001,0.033,0.033$, and 0.05 , respectively) (Table II).

We then analyzed the PFS and OS of the 77 patients by the Kaplan-Meier method. Patient age (older or $\leq 60$ years), the duration of PPV therapy lasting more or $\leq 3$ months, and concurrent conventional hormonal therapies were each significantly associated with both PFS and OS, age over 60 years (Fig. S1 A and B), duration of PPV therapy over 3 months (Fig. S1C and D), and concurrent hormonal therapies
(Fig. S1E and F) were significantly associated with better prognosis. ( $\mathrm{P}=0.0419,<0.0001,0.0002$ in $\mathrm{PFS}$, and $\mathrm{P}=0.0019$, $<0.0001,0.0006$ in OS).

We further analyzed the association of anti-PRA IgG in age subgroups (Fig. 4). We determined the survival curves comparing patients $\leq 60$ years old and those $>60$ years old who did or did not exhibit increased anti-PRA IgG after PPV therapy. Although it was marginally associated with PFS (Fig. 4A, log-rank $\mathrm{P}=0.058$ ), an increase in anti-PRA IgG was significantly associated with OS in the $>60$-year-old patients (Fig. 4B, log-rank $\mathrm{P}=0.008$ ). In contrast, this significance was not observed in the patients $\leq 60$ years old for PFS $(\mathrm{P}=0.422)$ or $\mathrm{OS}(\mathrm{P}=0.127)$. 


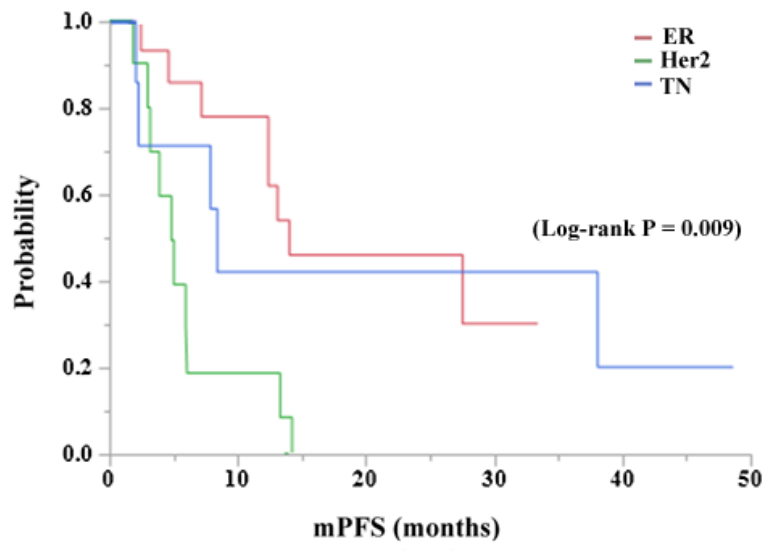

Figure 3. Survival curve analyses of anti-PRA IgG response in the three intrinsic subtypes. The median PFS of ER+/HER2-patients with metastatic recurrent breast cancer in the anti-PRA increase group was 13.6 months, whereas that of patients with HER2+ was 4.8 months. Patients with triple-negative breast cancer was 8.1 months (log-rank, $\mathrm{P}=0.009)$. PRA, prostate related antigen; PFS, progression free survival; ER, estrogen receptor; $m$, median.

\section{Discussion}

The serum PSA level is one of the most valuable serum tumor markers used for the standard diagnosis and clinical management of prostate cancer $(6,15,16)$. In contrast, the predictive potential of the PRA expression in breast cancer (particularly the expression of PSA) for prognosis is still controversial. Several research groups have reported that PSA positivity was significantly associated with normal breast tissues, with benign, smaller tumors, and with progesterone and/or androgen receptor positivity. Those researchers proposed that PRA could be a valuable tool for the prediction of a favorable breast cancer outcome $(2,17)$, whereas those were inversely associated with stage III or IV advanced breast cancer (1). In addition, we observed the lesser or lower expression of those antigens on refractory mrBC specimens in our preliminary study (7). Taken together, the above-described results suggest that plasma anti-PRA IgG levels could be an alternate biomarker for the prediction of breast cancer progression.

However, recent research has indicated that immunologic factors, such as tumor-infiltrating lymphocytes (TILs) and PD-1/PD-L1 expression, have a significant impact on the clinical outcome of patients with early-stage breast cancer (18-20). Novel immunotherapeutic strategies, including PPV therapy, have also showed considerable promise in the immune system response to breast tumors in the majority of patients with $\operatorname{mrBC}(7,21,22)$. Several studies showed that the IgG response to antigens of mucin-1 (MUC-1) or other tumor-associated antigens on breast cancer might contribute to a better prognosis (23-25).

To the best of our knowledge, there has been no research investigating the clinical significance associated with anti-PRA IgG for metastatic recurrent breast cancer. We thus focused in the present study on patients with refractory $\mathrm{mrBC}$, and we examined their plasma pre- and postvaccination levels of anti-PRA IgG. The results of our analyses revealed that anti-PRA IgG levels were increased in 31 of the $77(40.3 \%)$ patients after PPV therapy.
It is well recognized that the cancer immunity cycle consists of several steps, including the release of cancer antigens from cell death, their presentation by antigen-presenting cells to $\mathrm{T}$ cells, the activation of T cells, their infiltration to the cancer tissues, the elimination of cancer cells, and the release of cancer antigens. The newly released cancer antigens have been described as antigen spreading phenomena after peptide vaccination. This epitope-spreading responses have been observed in $\mathrm{HER}_{2}{ }^{+}$patients following immunization with the HER2 peptide vaccine $(26,27)$, and Gulley et al (6) found that using the vaccine (Prostvac) against PSA in combination with radiation therapy caused antigen spreading immune responses to a number of prostate antigens, and this vaccine showed evidence of improved survival (5). We also reported the PPV-induced antigen spreading was a favorable biomarker for gynecological cancers $(28,29)$.

Our present findings consequently showed that peptide vaccines derived from tumor-associated antigens (TAAs) induced a humoral IgG response to a variety of PRAs including PSA, PSMA, and PAP in patients with $\mathrm{mrBC}$, and that this treatment-associated anti-PRA IgG response demonstrates potential prognostic significance for monitoring the outcome of peptide vaccine treatment for patients with $\mathrm{mrBC}$.

Although the mechanisms by which high plasma IgG levels against PRA are associated with better survival have not been fully explained, it has been suggested that PRA, in particular plasma PSA, is associated with a favorable prognosis and that its induction is an unfavorable factor for breast cancer patients with $\mathrm{ER}^{+}$cancer, but not with androgens and progestins (30-32). Nevertheless, we did not analyze the expression of androgen receptor (AR), which is widely expressed in breast cancer. As is the case for ER, AR expression is associated with a more favorable prognosis among patients with $\mathrm{ER}^{+}$breast cancer $(33,34)$.

Our results showed that higher post-vaccinated plasma IgG antibody levels to PRA were associated with better PFS and OS, and it should be noted that our results provide the first evidence that the plasma anti-PRA IgG level might be a useful prognostic biomarker for peptide vaccine therapy in patients with $\mathrm{mrBC}$.

Our analyses revealed that patients who underwent a longer duration of PPV therapy had significantly better PFS and OS outcomes, as did the $\mathrm{ER}^{+} / \mathrm{HER} 2$-patients $(\mathrm{n}=18 ; 58.1 \%)$ in the anti-PRA increase group who were simultaneously given a peptide vaccine with an aromatase inhibitor (Table I, Fig. S1). In contrast, the $\mathrm{ER}^{+} \mathrm{mrBC}$ patients without an increased anti-PRA IgG response (the anti-PRA no-increase group) showed that AI treatment along with the vaccination could not improve the outcome for these patients, as there was no significant difference in survival between the $\mathrm{ER}^{+}$patients and the $\mathrm{HER} 2^{+}$or TN patients (Fig. 3). Consequently, our findings suggest that conventional hormonal therapy combined with peptide vaccines for postmenopausal mrBC patients, particularly for those over 60 years old, might be a novel and effective treatment strategy.

Recent evidence has also shown that the monoclonal antibody trastuzumab can kill HER $2^{+}$breast cancer cells not only by blocking HER2 signaling, but also through immune mechanisms that include antibody-dependent cellular cytotoxicity and complement-dependent cytotoxicity. In addition, the administration of trastuzumab was observed to induce adaptive immunity including both T-cell and antibody responses 
Table II. Cox analysis in patients with mrBC who received PPVs for PFS and OS.

\begin{tabular}{|c|c|c|c|c|c|c|c|c|c|}
\hline \multirow[b]{3}{*}{ Characteristics } & \multirow{3}{*}{$\begin{array}{l}\text { No. of } \\
\text { patients }\end{array}$} & \multicolumn{4}{|c|}{ PFS } & \multicolumn{4}{|c|}{ OS } \\
\hline & & \multirow{2}{*}{$\begin{array}{l}\text { Univariate } \\
\text { analysis } \\
\text { P-value }\end{array}$} & \multicolumn{3}{|c|}{ Multivariate analysis } & \multirow{2}{*}{$\begin{array}{c}\begin{array}{c}\text { Univariate } \\
\text { analysis }\end{array} \\
\text { P-value }\end{array}$} & \multicolumn{3}{|c|}{ Multivariate analysis } \\
\hline & & & $\mathrm{HR}$ & $95 \% \mathrm{CI}$ & P-value & & $\mathrm{HR}$ & $95 \% \mathrm{CI}$ & P-value \\
\hline Age, $<59$ vs. $>60$ years & $50 / 27$ & 0.303 & 0.49 & $0.25-0.94$ & 0.03 & 0.037 & 2.1 & $1.09-4.28$ & 0.025 \\
\hline Performance status, 0 vs. 1 & $69 / 8$ & 0.451 & & & & 0.225 & & & \\
\hline $\begin{array}{l}\text { Post-PPV anti-PRA mAb } \\
\text { boosting, + vs. - a }\end{array}$ & $31 / 46$ & 0.023 & 0.46 & $0.22-0.96$ & 0.039 & 0.463 & & $0.41-1.58$ & 0.542 \\
\hline ER+ vs. HER2- & 44 & 0.337 & & & & 0.592 & & $0.21-1.49$ & 0.267 \\
\hline HER-2 positive & 15 & 0.049 & 9.17 & $1.33-95.2$ & 0.023 & 0.843 & & & \\
\hline Triple negative & 18 & 0.635 & & & & 0.507 & & & \\
\hline $1-3$ regimens vs. $>4$ regimens $s^{b}$ & $36 / 41$ & 0.009 & 2.2 & $1.09-4.57$ & 0.029 & 0.088 & & & \\
\hline $\begin{array}{l}\text { Total site of metastases } \\
\text { (range: } 1-4):<2 />2\end{array}$ & & 0.171 & & & & 0.234 & & & \\
\hline $\begin{array}{l}\text { Median times of peptide } \\
\text { vaccination (months): }<3 />3\end{array}$ & $40 / 37$ & 0.009 & 0.1 & $0.04-0.26$ & 0.001 & $<0.0001$ & 0.08 & $0.03-0.21$ & $<0.0001$ \\
\hline Anti-Her2 therapy & 15 & 0.88 & & & & 0.255 & 0.37 & $0.14-0.92$ & 0.033 \\
\hline Hormonal therapy & 30 & 0.299 & 0.48 & $0.22-0.99$ & 0.048 & 0.131 & 0.48 & $0.23-0.94$ & 0.033 \\
\hline $\begin{array}{l}\text { Bisphosphonate/Anti-RNAKL } \\
\text { therapy }\end{array}$ & 21 & 0.261 & & & & 0.001 & 0.48 & $0.22-1.01$ & 0.05 \\
\hline
\end{tabular}

${ }^{\mathrm{a}}+$, anti-PRA increase vs. - , anti-PRA no-increase. ${ }^{\mathrm{b}}$ Number of previous chemotherapy regimens before receiving PPV. PFS, progression free survival; OS, overall survival; HR, hazard ratio; CI, confidence interval; ER, estrogen receptor.

A

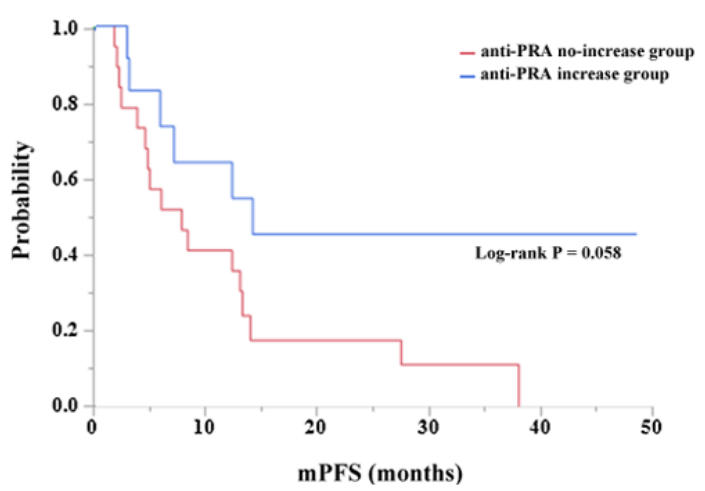

B

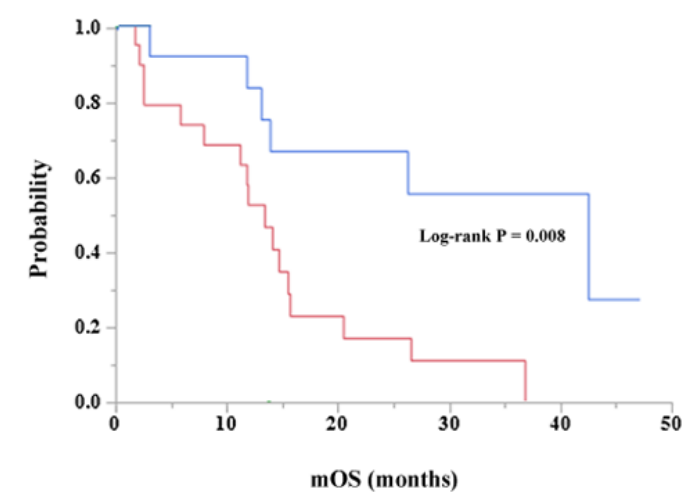

Figure 4. Survival curve analyses for patients ( $<60$ and $\geq 60$ years) with or without an anti-PRA IgG response after personalized peptide vaccine therapy. Of the 27 patients $\geq 60$ years, those in the anti-PRA increase group $(n=12)$ demonstrated significantly longer PFS. (A) PFS log-rank was $\mathrm{P}=0.058$ and $(\mathrm{B}) \mathrm{OS}$ log-rank was $\mathrm{P}=0.008$ compared with those in the anti-PRA no-increase group $(n=15)$. PRA, prostate related antigen; PFS, progression free survival; OS, overall survival; m, median.

in patients with HER2 ${ }^{+}$breast cancer $(35,36)$. Clinical observations have also demonstrated that peptide-based HER2 vaccines administered concurrently with trastuzumab resulted in potent and specific immune activation and were associated with better survival $(21,37)$.

However, there is evidence suggesting that anti-RANKL therapy (with denosumab, a fully human IgG2 monoclonal antibody specific to RANKL) may induce divergent effects in the immune system beyond the effects on bone, which is also true of the bisphosphonate Zometa ${ }^{\circledR}$ (zoledronic acid) (38-40).
Moreover, combination therapies targeting RANKL-RANK signaling can be used to prevent subsequent metastatic disease in breast cancer (41).

Therefore, our results are consistent with the supposition that immunotherapeutic strategies using peptide vaccines, such as PPV therapy, can be efficiently combined with conventional therapies such as hormonal, anti-HER2, and bisphosphonate/anti-RANKL therapies for mrBC patients whose cancer has been resistant to previous standard cytotoxic chemotherapies. Notably, this novel complementary integrative treatment 
might be more effective in older postmenopausal mrBC patients ( $\geq 60$ years old).

Although we analyzed 77 vaccinated patients and observed the prognostic predictive possibility of anti-PRA IgG, our study has some limitations. These include the presence of multiple confounding factors in the examination of prognostic biomarkers, the small sample size with more HER2 ${ }^{+}$patients in the PRA response group, the single-arm data set, and, finally, the combination treatment with standard chemotherapy, endocrine therapy, and/or bisphosphonate/anti-RANKL therapy. In summary, our data show that plasma IgG antibodies to PRA increased in patients with $\mathrm{mrBC}$, and the presence of these antibodies was associated with better survival in the patients who were treated using personalized peptide vaccines, particularly in the older postmenopausal $\mathrm{ER}^{+} \mathrm{mrBC}$ patients. Additional prospective studies with larger numbers of patients are needed in order to confirm the clinical importance of anti-PRA IgG in patients with $\mathrm{mrBC}$ in relation to tumor progression and therapeutic implications.

\section{Acknowledgements}

Professor Tatsuyuki Kakuma of Kurume University Biostatistics Center was responsible for the supervision of the statistical analysis.

\section{Funding}

The present study was supported by grants from the Ministry of Education, Culture, Sports, Science and Technology of Japan.

\section{Availability of data and materials}

All data generated or analyzed during this study are included in this published article.

\section{Authors' contributions}

SSaku, UT and KI are responsible for the study design, analysis of data and drafting the manuscript. UT, AY and YA are responsible for the supervision of analysis of data. S Sakurai, YT and SShichijo are responsible for the acquisition and interpretation of data. SSaku is responsible for the material and technical support. All authors read and approved the final manuscript.

\section{Ethics approval and consent to participate}

The study protocol was approved by the Kurume University Ethical Committee and registered in the UMIN Clinical Trials Registry (no. UMIN000001844). All patients were given a full explanation of the protocol, and provided their informed consent prior to enrollment in the clinical trial of PPV therapy and subsequent data analysis.

\section{Patient consent for publication}

Not applicable.

\section{Competing interests}

Akira Yamada is a part-time executive of Bright Pass Biotherapeutics. Akira Yamada and Shigeki Shichijo have
Bright Pass Biotherapeutics stock. Kyogo Itoh received research funding from Taiho Pharmaceutical Co. Ltd. The remaining authors declare that they have no competing interests.

\section{References}

1. Yu H, Diamandis EP, Levesque M, Giai M, Roagna R, Ponzone R, Sismondi P, Monne M and Croce CM: Prostate specific antigen in breast cancer, benign breast disease and normal breast tissue. Breast Cancer Res Treat 40: 171-178, 1996.

2. Black MH and Diamandis EP: The diagnostic and prognostic utility of prostate-specific antigen for diseases of the breast. Breast Cancer Res Treat 59: 1-14, 2000.

3. Mannello F and Gazzanelli G: Prostate-specific antigen (PSA/hK3): A further player in the field of breast cancer diagnostics? Breast Cancer Res 3: 238-243, 2001.

4. Alanen KA, Kuopio T, Collan YU, Kronqvist P, Juntti L and Nevalainen TJ: Immunohistochemical labelling for prostate-specific antigen in breast carcinomas. Breast Cancer Res Treat 56: 169-176, 1999.

5. Kantoff PW, Schuetz TJ, Blumenstein BA, Glode LM, Bilhartz DL, Wyand M, Manson K, Panicali DL, Laus R, Schlom J,et al: Overall survival analysis of a phase II randomized controlled trial of a Poxviral-based PSA-targeted immunotherapy in metastatic castration-resistant prostate cancer. J Clin Oncol 28: 1099-1105, 2010.

6. Gulley JL, Madan RA, Tsang KY, Jochems C, Marté JL, Farsaci B, Tucker JA, Hodge JW, Liewehr DJ, Steinberg SM, et al: Immune impact induced by PROSTVAC (PSA-TRICOM), a therapeutic vaccine for prostate cancer. Cancer Immunol Res 2: 133-141, 2014.

7. Takahashi R, Toh U, Iwakuma N, Takenaka M, Otsuka H, Furukawa M, Fujii T, Seki N, Kawahara A, Kage M, et al: Feasibility study of personalized peptide vaccination for metastatic recurrent triple-negative breast cancer patients. Breast Cancer Res 16: R70, 2014.

8. Sasada T, Komatsu N, Suekane S, Yamada A, Noguchi M and Itoh K: Overcoming the hurdles of randomised clinical trials of therapeutic cancer vaccines. Eur J Cancer 46: 1514-1519, 2010.

9. Terasaki M, Shibui S, Narita Y, Fujimaki T, Aoki T, Kajiwara K, Sawamura Y, Kurisu K, Mineta T, Yamada A and Itoh K: Phase I trial of a personalized peptide vaccine for patients positive for human leukocyte antigen-A24 with recurrent or progressive glioblastoma multiforme. J Clin Oncol 29: 337-344, 2011.

10. Yanagimoto $\mathrm{H}$, Shiomi $\mathrm{H}$, Satoi S, Mine T, Toyokawa $\mathrm{H}$, Yamamoto T, Tani T, Yamada A, Kwon AH, Komatsu N, et al: A phase II study of personalized peptide vaccination combined with gemcitabine for non-resectable pancreatic cancer patients. Oncol Rep 24: 795-801, 2010.

11. Hattori T, Mine T, Komatsu N, Yamada A, Itoh K, Shiozaki H and Okuno K: Immunological evaluation of personalized peptide vaccination in combination with UFT and UZEL for metastatic colorectal carcinoma patients. Cancer Immunol Immunother 58: 1843-1852, 2009.

12. Noguchi M, Mine T, Komatsu N, Suekane S, Moriya F, Matsuoka K, Yutani S, Shichijo S, Yamada A, Toh U, et al: Assessment of immunological biomarkers in patients with advanced cancer treated by personalized peptide vaccination. Cancer Biol Ther 10: 1266-1279, 2010.

13. Komatsu N, Shichijo S, Nakagawa M and Itoh K: New multiplexed flow cytometric assay to measure anti-peptide antibody: A novel tool for monitoring immune responses to peptides used for immunization. Scand J Clin Lab Invest 64: 535-545, 2004.

14. Matsueda S, Komatsu N, Kusumoto K, Koga S, Yamada A, Kuromatsu R, Yamada S, Seki R, Yutani S, Shichijo S, et al: Humoral immune responses to CTL epitope peptides from tumor-associated antigens are widely detectable in humans: A new biomarker for overall survival of patients with malignant diseases. Dev Comp Immunol 41: 68-76, 2013.

15. Gulley JL, Arlen PM, Bastian A, Morin S, Marte J, Beetham P, Tsang KY, Yokokawa J, Hodge JW, Ménard C, et al: Combining a recombinant cancer vaccine with standard definitive radiotherapy in patients with localized prostate cancer. Clin Cancer Res 11: 3353-3362, 2005.

16. Noguchi M, Koga N, Moriya F and Itoh K: Immunotherapy in prostate cancer: Challenges and opportunities. Immunotherapy 8: 69-77, 2016. 
17. Yu H, Levesque MA, Clark GM and Diamandis EP: Prognostic value of prostate-specific antigen for women with breast cancer: A large United States cohort study. Clin Cancer Res 4: 1489-1497, 1998.

18. Takenaka M, Seki N, Toh U,Hattori S, Kawahara A, Yamaguchi T, Koura K, Takahashi R, Otsuka H, Takahashi H, et al: FOXP3 expression in tumor cells and tumor-infiltrating lymphocytes is associated with breast cancer prognosis. Mol Clin Oncol 1: 625-632, 2013

19. Okabe M, Toh U, Iwakuma N, Saku S, Akashi M, Kimitsuki Y, Seki N, Kawahara A, Ogo E, Itoh K and Akagi Y: Predictive factors of the tumor immunological microenvironment for long-term follow-up in early stage breast cancer. Cancer Sci 108: 81-90, 2017.

20. Sakamoto S, Matsueda S, Takamori S, Toh U, Noguchi M, Yutani S, Yamada A, Shichijo S, Yamada T, Suekane S, et al: Immunological evaluation of peptide vaccination for cancer patients with the HLA-A11(+) or -A33(+) allele. Cancer Sci 108: 598-603, 2017.

21. Disis ML, Wallace DR, Gooley TA, Dang Y, Slota M, Lu H, Coveler AL, Childs JS, Higgins DM, Fintak PA, et al: Concurrent trastuzumab and HER2/neu-specific vaccination in patients with metastatic breast cancer. J Clin Oncol 27: 4685-4692, 2009.

22. Higgins M, Curigliano G, Dieras V, Kuemmel S, Kunz G, Fasching PA, Campone $\mathrm{M}$, Bachelot $\mathrm{T}$, Krivorotko $\mathrm{P}$, Chan S, et al: Safety and immunogenicity of neoadjuvant treatment using WT1-immunotherapeutic in combination with standard therapy in patients with WT1-positive Stage II/III breast cancer: A randomized phase I study. Breast Cancer Res Treat 162: 479-488, 2017.

23. Isla Larrain MT, Colussi AG, Demichelis SO, Barbera A, Creton A, Segal-Eiras A and Croce MV: Humoral immune response against tumoral mucin 1 (MUC1) in breast cancer patients. Int J Biol Markers 28: 318-325, 2013.

24. Clive KS, Tyler JA, Clifton GT, Holmes JP, Ponniah S, Peoples GE and Mittendorf EA: The GP2 peptide: A HER2/neu-based breast cancer vaccine. J Surg Oncol 105: 452-458, 2012.

25. Mittendorf EA, Clifton GT, Holmes JP, Schneble E, van Echo D, Ponniah S and Peoples GE: Final report of the phase I/II clinical trial of the E75 (nelipepimut-S) vaccine with booster inoculations to prevent disease recurrence in high-risk breast cancer patients. Ann Oncol 25: 1735-1742, 2014.

26. Disis ML, Goodell V, Schiffman K and Knutson KL: Humoral epitope-spreading following immunization with a HER-2/neu peptide based vaccine in cancer patients. J Clin Immunol 24: 571-578, 2004

27. Disis ML, Schiffman K, Guthrie K, Salazar LG, Knutson KL, Goodell V, dela Rosa C and Cheever MA: Effect of dose on immune response in patients vaccinated with an her-2/neu intracellular domain protein-based vaccine. J Clin Oncol 22: 1916-1925, 2004.

28. Kawano K, Tsuda N, Matsueda S, Sasada T, Watanabe N, Ushijima K, Yamaguchi T, Yokomine M, Itoh K, Yamada A and Kamura T: Feasibility study of personalized peptide vaccination for recurrent ovarian cancer patients. Immunopharmacol Immunotoxicol 36: 224-236, 2014.
29. Kawano K, Tsuda N, Waki K, Matsueda S, Hata Y, Ushijima K, Itoh K, Yamada A and Kamura T: Personalized peptide vaccination for cervical cancer patients who have received prior platinum-based chemotherapy. Cancer Sci 106: 1111-1117, 2015.

30. Zarghami N, Grass L and Diamandis EP: Steroid hormone regulation of prostate-specific antigen gene expression in breast cancer. Br J Cancer 75: 579-588, 1997.

31. Yu H, Diamandis EP, Zarghami N and Grass L: Induction of prostate specific antigen production by steroids and tamoxifen in breast cancer cell lines. Breast Cancer Res Treat 32: 291-300, 1994.

32. Zarghami N and Diamandis EP: Detection of prostate-specific antigen mRNA and protein in breast tumors. Clin Chem 42: 361-366, 1996.

33. Hu R, Dawood S, Holmes MD, Collins LC, Schnitt SJ, Cole K, Marotti JD, Hankinson SE, Colditz GA and Tamimi RM: Androgen receptor expression and breast cancer survival in postmenopausal women. Clin Cancer Res 17: 1867-1874, 2001.

34. Vera-Badillo FE, Templeton AJ, de Gouveia P, Diaz-Padilla I, Bedard PL, Al-Mubarak M, Seruga B, Tannock IF, Ocana A and Amir E: Androgen receptor expression and outcomes in early breast cancer: A systematic review and meta-analysis. J Natl Cancer Inst 106: djt319, 2014.

35. Bianchini G and Gianni L: The immune system and response to HER2-targeted treatment in breast cancer. Lancet Oncol 15: e58-e68, 2014.

36. Bianchini G, Pusztai L, Pienkowski T, Im YH, Bianchi GV, Tseng LM, Liu MC, Lluch A, Galeota E, Magazzù D, et al: Immune modulation of pathologic complete response after neoadjuvant HER2-directed therapies in the NeoSphere trial. Ann Oncol 26: 2429-2436, 2015.

37. Soliman H: Immunotherapy strategies in the treatment of breast cancer. Cancer Control 20: 17-21, 2013.

38. Gober HJ, Kistowska M, Angman L, Jenö P, Mori L and De Libero G: Human T cell receptor gammadelta cells recognize endogenous mevalonate metabolites in tumor cells. J Exp Med 197: 163-168, 2003.

39. Hewitt RE, Lissina A, Green AE, Slay ES, Price DA and Sewell AK: The bisphosphonate acute phase response: rapid and copious production of proinflammatory cytokines by peripheral blood gd T cells in response to aminobisphosphonates is inhibited by statins. Clin Exp Immunol 139: 101-111, 2005.

40. Cheng ML and Fong L: Effects of RANKL-targeted therapy in immunity and cancer. Front Oncol 3: 329, 2014

41. Tan W, Zhang W, Strasner A, Grivennikov S, Cheng JQ, Hoffman RM and Karin M: Tumour-infiltrating regulatory T cells stimulate mammary cancer metastasis through RANKL-RANK signalling. Nature 470: 548-553, 2011.

This work is licensed under a Creative Commons Attribution-NonCommercial-NoDerivatives 4.0 International (CC BY-NC-ND 4.0) License. 